\title{
Direct restoration of proximal caries by means of ormocers and universal adhesives - Clinical case presentation
}

\author{
Restaurarea directă a leziunilor carioase proximale cu ormoceri şi adezivi \\ universali - prezentare de caz clinic
}

\section{Ana Cristina Hodobeț, Cornelia Bîcleşanu, Andreea Tudose, Anamaria Florescu}

\author{
Facultatea de Medicină Dentară, Universitatea „Titu Maiorescu“, Bucureşti, România
}

\begin{abstract}
Introduction. Patients increased aesthetic requirements have determined the use of composite resins for the restoration of posterior proximal lesions. But one of their defects is the high polymerization shrinkage. Admira Fusion is the first "nano-ORMOCER" made by Nano-hybrid technology and ORMOCER (ORganic MOdified CERamic) which have a $50 \%$ lower polymerization shrinkage compared to conventional composite materials, also lower contraction stress, high surface hardness and marginal resistance. Futurabond $U$ is a universal adhesive which associated with Admira Fusion accomplishes a restoration with aesthetic and functional performances.

Case presentation. The patient presented for aesthetic restoration of tooth 45 which showed no painful pathology. For the restoration, Admira Fusion (Voco) and Futurabond U (Voco) were chosen and applied according to minimally invasive direct adhesive technique and for compaction, Compothixo instrument was used.

Conclusions. The material and the work method have led to the achievement of a restoration that satisfies the aesthetic and functional principles.
\end{abstract}

Keywords: nanohybrid ORMOCER®, universal adhesive, proximal lesions of posterior teeth

\begin{abstract}
REZUMAT
Introducere. Creşterea cerinţelor estetice ale pacienţilor au determinat utilizarea răşinilor compozite pentru refacerea leziunilor proximale posterioare. Acestea prezintă contracţie de polimerizare mare, care reprezintă unul dintre defectele lor. Admira Fusion este primul "nano-ORMOCER“ realizat prin tehnologia Nano-hibrid şi ORMOCER (ORganic MOdified CERamic) care au contracţie de polimerizare cu $50 \%$ mai mică în comparaţie cu materialele compozite convenţionale, stres de contracţie mai mic, duritate superficială ridicată şi rezistenţă marginală. Futurabond $U$ este un adeziv universal care asociat cu Admira Fusion realizează o restaurare cu performanţe estetice şi funç̧ionale.

Prezentare de caz. Pacienta s-a prezentat pentru refacerea fizionomică la 45, fără patologie dureroasă. S-a optat pentru refacerea cu Admira Fusion (Voco) şi Futurabond U (Voco) aplicate conform tehnicii adezive directe minim invazive şi compactare cu spatula Compothixo.

Concluzii. Materialul şi metoda de lucru utilizate au determinat obţinerea unei restaurări care satisface principiile fizionomice şi funcţionale.
\end{abstract}

Cuvinte cheie: nano-ormocer, adeziv universal, leziuni proximale, dinţi posteriori

\section{INTRODUCERE}

Restaurările directe reprezintă o manoperă frecvent utilizată în cabinetele dentare, iar jumătate sunt restaurări de clasa a-2-a.

Preparațiile pentru restaurarea leziunilor proximale posterioare prezintă câteva puncte nevralgice precum adaptarea la nivelul peretelui gingival şi realizarea punctului de contact proximal.
Admira Fusion este un material cu tehnologie nano-ormocer care a apărut recent pe piața produselor dentare (2014) din dorința de a compensa dezavantajele pe care le au răşinile compozite.

Un ormocer este o structură moleculară hibridă care combină nanocomponente organice şi anorganice prin metoda sol-gel $(1,2)$.

Deoarece matricea organică şi particulele de umplutură se bazează doar pe nano-particule de 
oxid de siliciu cu diametru de $20 \mathrm{~nm}$ (84\% greutate), neconținând monomeri clasici (www.voco.it), aceste materiale oferă o contracție de polimerizare mică $(1,25$ - vol.\%) şi o sigilare marginală optimă (3,78 Mpa) (VOCO, 2014) (3).

Alături de contracție scăzută şi rezistență crescută la uzură, ormocerii prezintă biocompatibilitate şi protecție împotriva cariilor (4).

Futurabond $U$ este primul adeziv universal cu priză dublă într-un sistem de livrare în doze de unică folosință. Adezivii universali, care par să reprezinte noua generație de adezivi permit efectuarea tehnicilor total etch sau self etch fără apariția hipersensibilității dentinare. Futurabond $U$ are calități care îl recomandă pentru tehnicile adezive: un $\mathrm{pH}$ mai ridicat care împiedică demineralizarea excesivă a dentinei deja demineralizate în tehnica total etch, prezența unui agent tensioactiv care crește higroscopicitatea şi reduce tensiunea superficială ameliorând aderența (5).

Pe smalţul preparat, infiltrarea adezivului se face simultan cu demineralizarea. La nivel dentinar, Futurabond U dizolvă smear layer-ul cu infiltrare profundă a fibrelor de colagen şi a canaliculelor radiculare cu adeziv (6).

\section{MATERIAL ŞI METODĂ}

Pacienta în vârstă de 36 de ani s-a prezentat pentru restaurarea unei leziuni carioase la 45 (Fig. 1). Subiectiv, s-a constatat prezența durerii la factori termici (rece), cât timp acționa factorul declanşator.

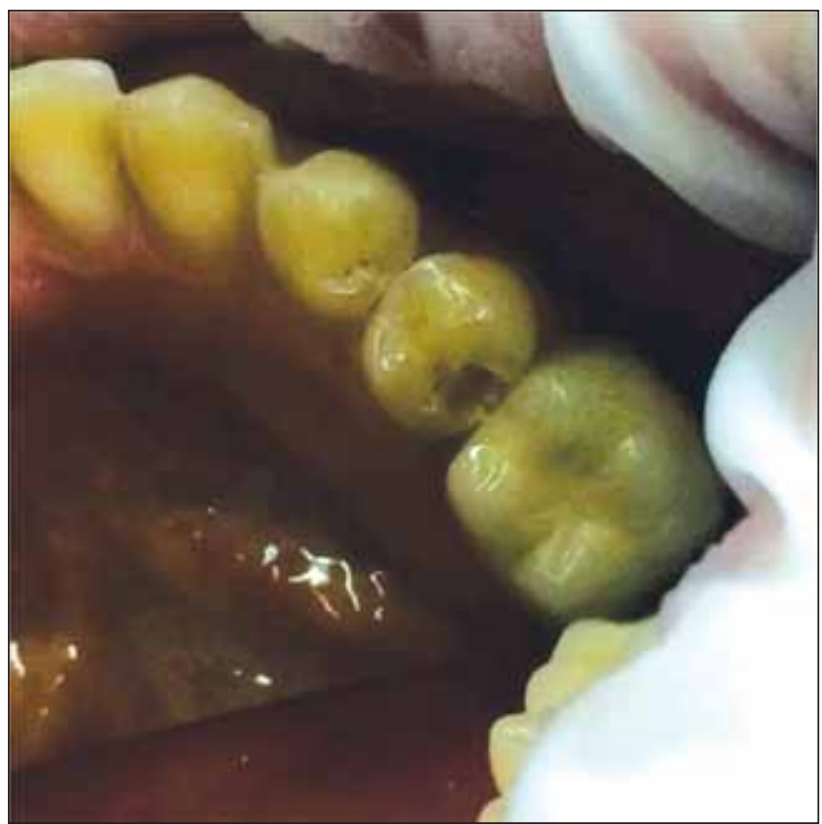

FIGURA 1. Aspect inițial

Examinarea clinică a arătat la inspecție existența unui proces carios cavitar, iar la palpare cu sonda prezența dentinei infectate şi absența durerii. Percuția în ax negativă şi testele de vitalitate pozitive asemănător cu al unui dinte normal ne-au confirmat diagnosticul de carie dentară simplă, astfel încât, pentru protecția pacientului, nu am mai indicat radiografia, ca examen complementar.

\section{PROTOCOL TERAPEUTIC}

Pentru o mai bună vizualizare a etapelor terapeutice s-a utilizat magnificația imaginilor cu oglinda intraorală (Fig. 2).



FIGURA 2. Oglinda intraorală

Detartraj, air-flow (AIR-FLOW ${ }^{\circledR}$ Hu Friedy) şi periaj profesional.

Alegerea culorii cu cheia Vita, s-a stabilit nuanța A2.

Izolare cu depărtătorul flexibil Optra-Gate (Ivoclar-Vivadent) asociat cu aspiratorul de salivă.

Prepararea cavităţii clasa a 2-a prin tehnici cât mai conservatore, care a constat în îndepărtarea dentinei infectate cu freza sferică la turație redusă, urmată de excavații progresive realizate manual cu excavatorul (Fig. 3, 4) şi finisarea marginilor de smalț de la nivelul pereților axiali şi al pragului gingival situat supragingival, cu freze de formă piriformă (Fig. 5).

După procedeul de excavare al dentinei infectate, controlul plăgii dentinare a fost făcut cu ajutorul lămpii cu ultraviolete Diagnostikset (Fig. 6). Această lampă permite vizualizarea zonelor dentinare demineralizate şi impregnate cu microorganisme, prin intermediul luminii ultraviolete, rezultând astfel o mai bună acuratețe a preparației dentinare în contextul limitării sacrificiului inutil de substanță dură dentară.

Aplicarea sistemului matrice - port matrice, cu profil conformat anatomic, urmată de inserarea în direcția oro-vestibulară a unei pene din lemn.

Demineralizarea a fost făcută selectiv doar la nivelul smalţului cu acid orto-fosforic $37 \%$ (Fig. 7). 


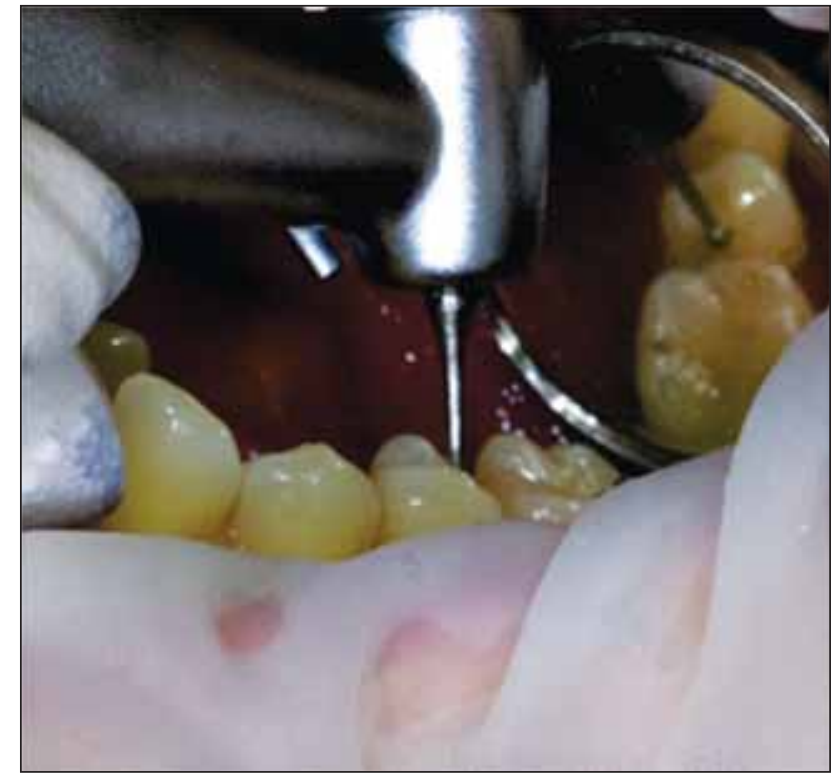

FIGURA 3. Îndepărtare dentină afectată

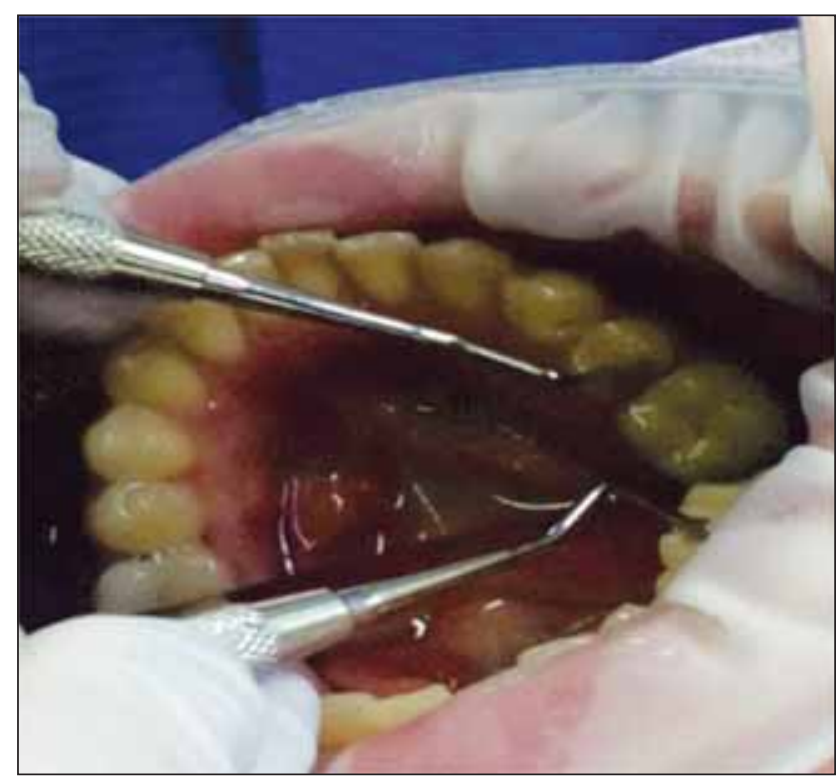

FIGURA 4. Îndepărtare dentină infectată



FIGURA 5. Determinare dentină cu Diagnostikset

Aplicarea bondingului de generația a 8-a Futurabond U (Voco) în straturi uniforme, timp de 20 de

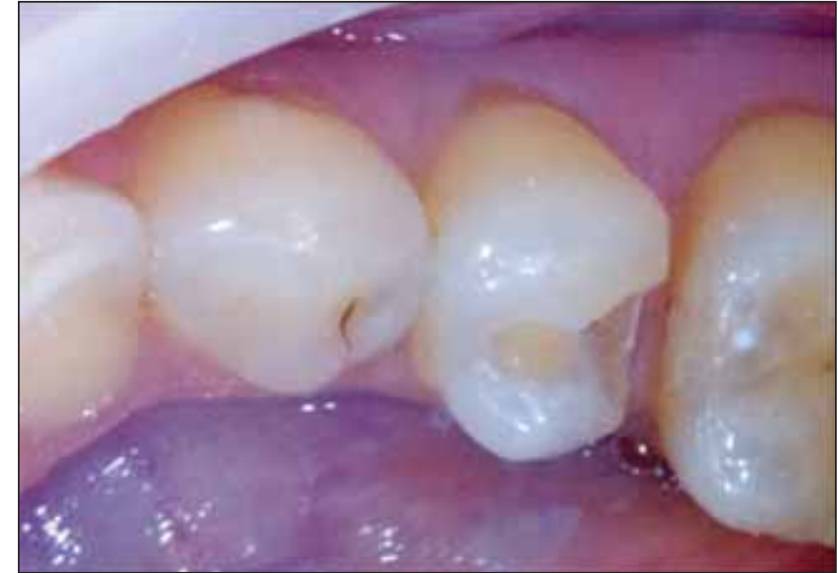

FIGURA 6. Aspect final preparație

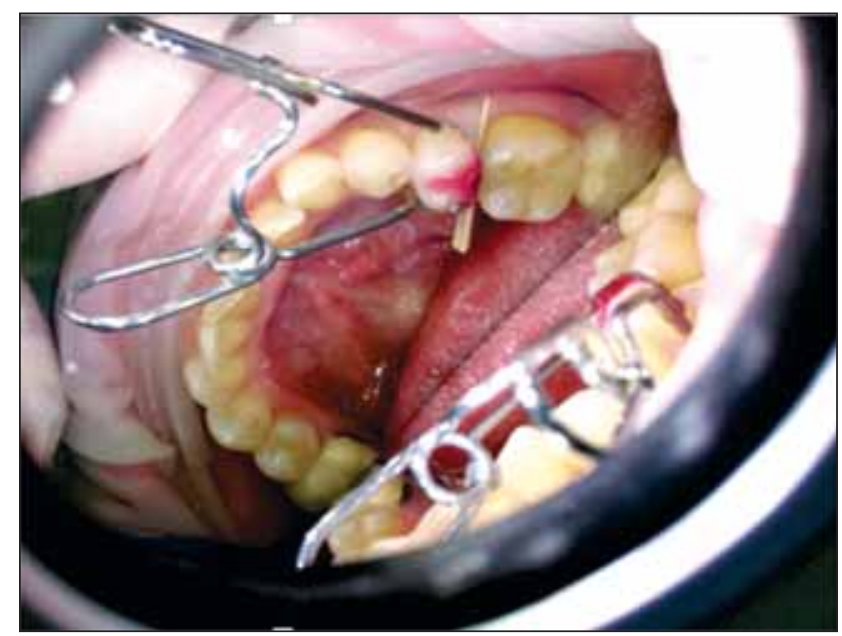

FIGURA 7. Demineralizare

secunde, apoi uscare uşoară cu spray-ul 5 secunde şi fotopolimerizare 10 secunde, conform indicațiilor producătorului (Fig. 8).

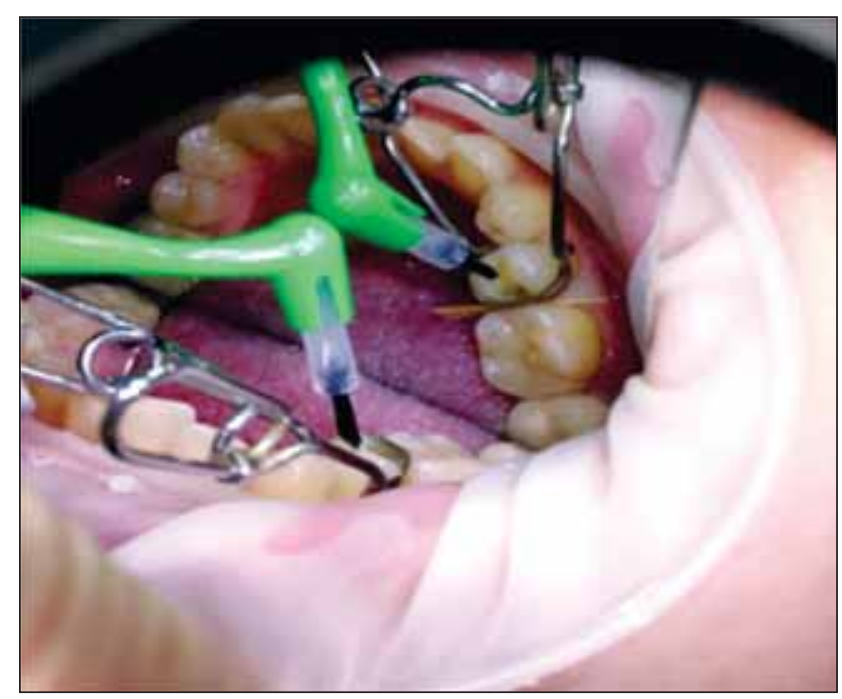

\section{FIGURA 8. Aplicare Futurabond U}

Aplicarea primului srat de nano-ormocer pe peretele gingival şi fotopolimerizare cu lampa Elipar cu led (3M ESPE), intensitate luminoasă 1.200 $\mathrm{mW} / \mathrm{cm}^{2}$, timp de 10 secunde. 
A urmat refacerea punctului de contact cu ajutorul instrumentului confecționat din silicon (PerForm $^{\mathrm{TM}}$ Garrison Dental Solutions) (TDV-USA), ce asigură concentrarea fasciculului luminii ultraviolete spre punctul de contact.

Mod de lucru: se aplică instrumentul în stratul al doilea de nano-ormocer nepolimerizat, se exercită manual uşoară presiune spre distal şi se fotopolimerizează prin capătul instrumentului (Fig. 9). Se obține un bun rezultat cu o tehnică de lucru relativ uşoară.

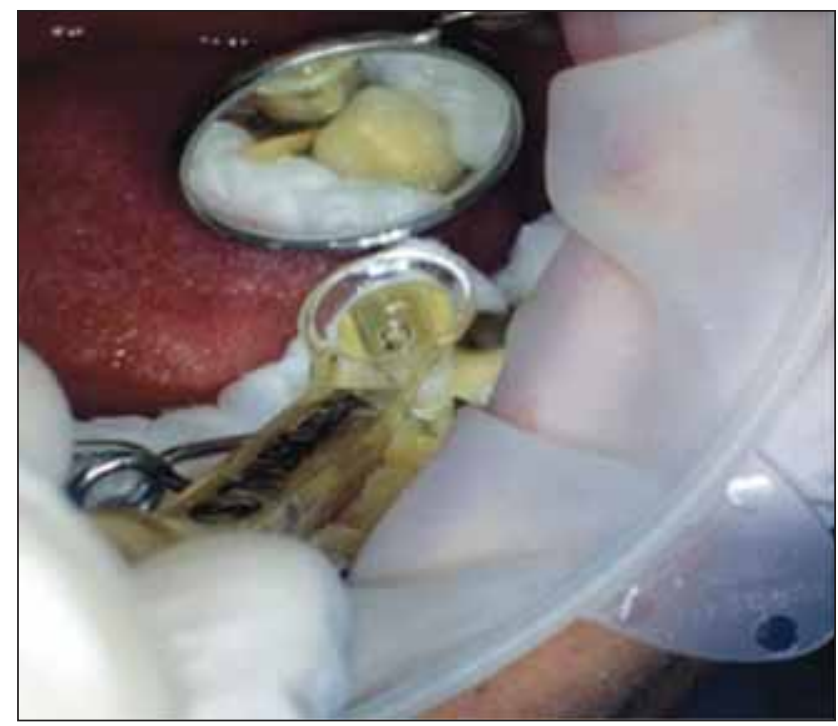

FIGURA 9. Realizare punct contact

Modelarea stratului următor de material s-a făcut cu ajutorul vibrațiilor furnizate de spatula Compothixo (Kerr), utilizând diverse vârfuri de modelare (Fig.10, 11).

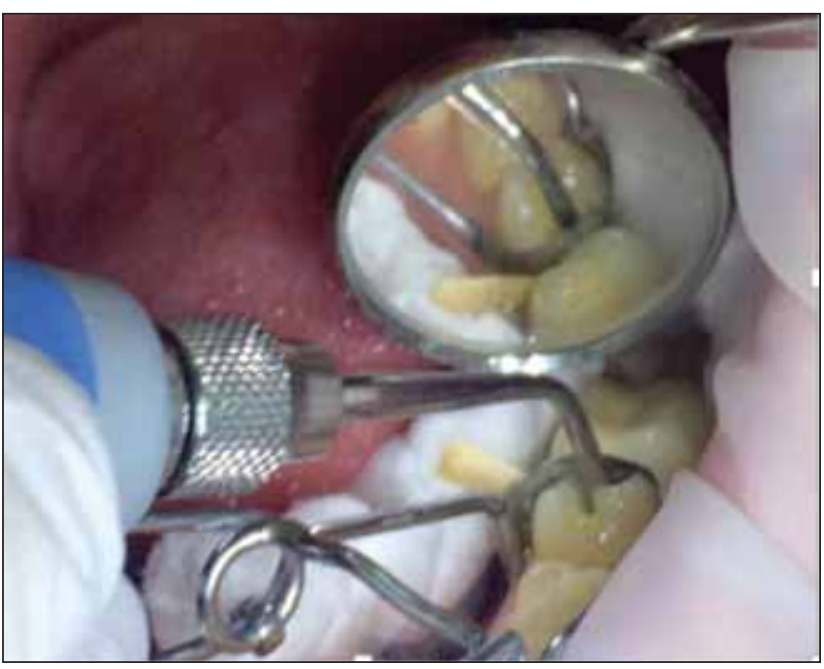

FIGURA 10. Compactare cu spatula Compothixo

A fost efectuată apoi o fotopolimerizare finală pe toată suprafața dentară.

Integrarea funcțională a cuprins mişcări de lateralitate şi propulsie, înregistrate cu hârtie de articulație (Bausch USA), de $40 \mu$ (Fig.12).

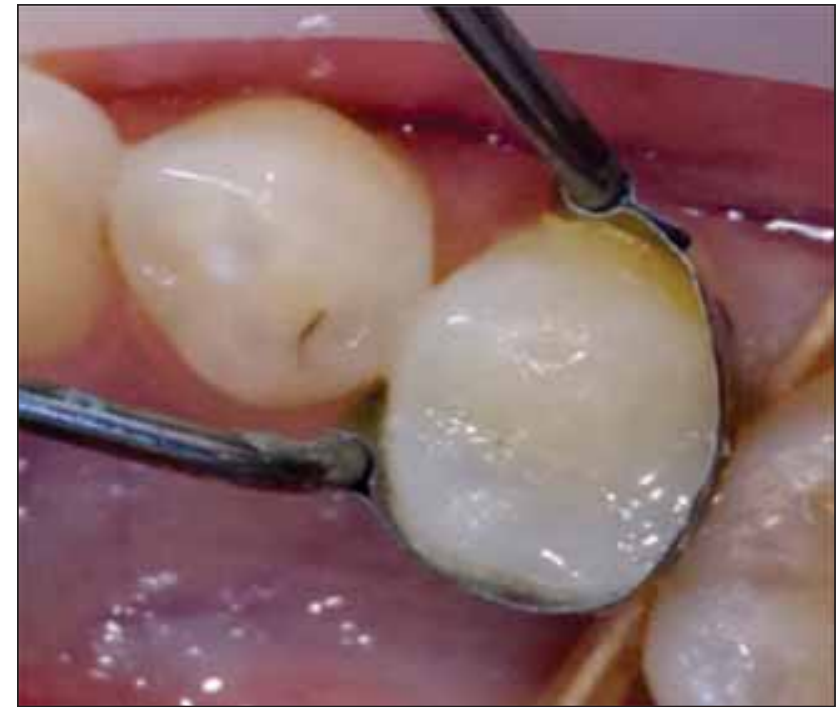

FIGURA 11. Aplicare Admira Fusion (Voco)



FIGURA 12. Adaptare în ocluzie

Interferențele ocluzale şi contactele premature au fost eliminate prin şlefuire cu pietre de Archansas.

Finisarea şi lustruirea efectuată cu discuri cu grade de abraziune descrescente TDV Praxis şi lustruirea cu discuri prevăzute cu fire de bumbac TDV Praxis, şi apoi cu gume de la $3 \mathrm{M}$ Espe şi pasta de lustruit TDV Polish. Finisarea şi lustruirea au fost minime, datorită bunei manevrabilităţi şi luciului conferite atât de calităţile nano-ormocerului, cât şi de tehnica vibratorie (Fig. 13).

$\mathrm{S}$-a verificat punctul de contact cu ața interdentară (Oral B). Conform criteriilor FDI 2010 pentru evaluarea clinică a restaurărilor (7), aspectul clinic acceptat presupune trecerea cu uşurință sau cu uşoară presiune a aței interdentare de $25 \mu \mathrm{m}$.

S-a recomandat pacientului să efectueze igiena dentară corectă cu aplicarea în plus a mijloacelor de igienizare a suprafețelor interdentare (ața dentară, periuțe interdentare) (Fig. 14, aspect final). 


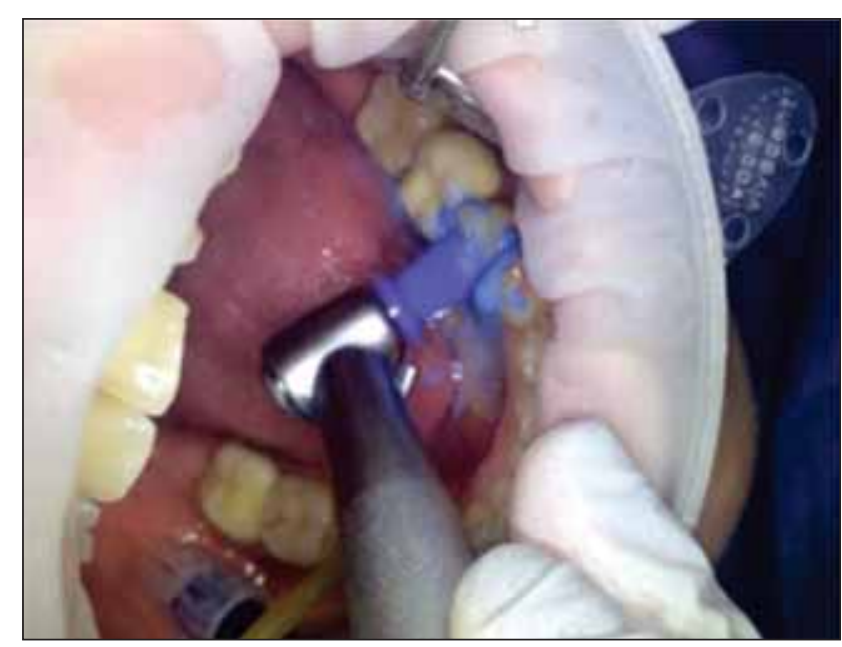

FIGURA 13. Lustruire



FIGURA 14. Aspect final

\section{REZULTATE ŞI DISCUȚII}

Cazul a încercat să rezolve unele dintre problemele care apar în restaurările leziunilor carioase proximo-ocluzale: adaptarea la pragul gingival, refacerea punctului de contact şi, nu în ultimul rând, alegerea unor materiale care să asigure, în egală

\section{BIBLIOGRAFIE}

1. Garapati S. Cuspal Movement and Microleakage in Premolar Teeth Restored with Posterior Restorative Materials. J Int Oral Health. 2014 Sep-Oct; 6(5): 47-50.

2. Bacchi A., Feitosa V.P., da Silva Fonseca A.S., et al. Shrinkage, stress, and modulus of dimethacrylate, ormocer, and silorane composites. J Conserv Dent. 2015; 18:384-388.

3. http://www.voco.com/au/product/Admira-Fusion/index.html

4. Kalra S., Singh A., Gupta M., et al. Ormocer: an aesthetic direct restorative material; an in vitro study comparing the marginal sealing ability of organically modified ceramics and a hybrid composite using an ormocer-based bonding agent măsură, rezistența şi estetica restaurărilor. Cazul clinic s-a axat pe descrierea unor tehnici indicate în astfel de restaurări, şi anume aplicarea stratificată a unui material nou, nano-ormocerul Admira Fusion (Voco), tehnica PushDistal pentru restabilirea punctului de contact, compactarea cu spatula Compothixo, iar rezultatele obținute au demonstrat eficiența lor materializată prin gradul de satisfacție al pacientei.

Adeziunea s-a efectuat cu Futurabond U, un adeziv universal nanoranforsat cu priză dublă, întrun pas. Cele mai recente materiale de pe piaţa adezivilor sunt ,adezivii universali“. În teorie, aceste sisteme au potenţialul de a simplifica şi accelera semnificativ protocoalele adezive şi pot într-adevăr să reprezinte următoarea evoluție a stomatologiei adezive (5).

Futurabond U conține un agent tensioactiv care creşte higroscopicitatea sa şi reduce tensiunea superficială, ameliorând aderența. Forma de prezentare este monodoza, care conține componentele produsului ce se combină în momentul aplicării. În acest fel se reduce posibilitatea evaporării care ar deteriora calitățile adezivului (6).

\section{CONCLUZII}

Tehnica de restaurare directă prin utilizarea Admira Fusion (Voco) şi Futurabond (Voco), executată în mod corespunzător, cu respectarea protocolului clinic de preparare şi restaurare, poate fi o opțiune viabilă pentru pacienții care solicită restaurare fizionomică.

Schema optimă de tratament se face individualizat, prin alegerea soluției terapeutice optime, în urma analizei minuțioase a tuturor factorilor clinici coroborați cu preferințele, opțiunile şi posibilitățile materiale ale fiecărui pacient în parte.

Conflict of interest: none declared Financial support: none declared

and a conventional fifth-generation bonding agent. Cont Clin Dent. 2012; 3:48-53.

5. Kaminer R. Adhésifs universels : comme bon vous semble. Esthétique Tribune Édition Française, http://www.voco.fr/fr/ product/futurabond-u/AB-Futurabond-U_Dr_-Kaminer_ Esthetique-Tribune_November-2015.pdf

6. http://www.voco.com/us/product/futurabond_u/VC-84001571-US.pdf

7. http://zep01793.dent.med.uni-muenchen.de/moodle/file. php/1/e-calib-tab2.html. 